\title{
Determinants of Postpartum Visits in Breastfeeding Mother
}

\author{
Eny Retna Ambarwati ${ }^{1}$, Endang Khoirunnisa ${ }^{2}$, Triantoro Safaria ${ }^{3}$ \\ ${ }^{1,2}$ Midwifery Academy of Yogyakarta, Indonesia \\ ${ }^{3}$ Department of Public Health Science, Universitas Ahmad Dahlan, Indonesia
}

\begin{tabular}{l}
\hline \hline Article Info \\
\hline Article history: \\
Received Nov 13, 2015 \\
Revised Jan 13, 2016 \\
Accepted Feb 27, 2016 \\
\hline
\end{tabular}

\section{Keyword:}

Breastfeeding

Maternal deaths

Mother

Postpartum visits

T-test

\begin{abstract}
Puerperal is likely in the occurrence of maternal deaths, and should receive health care during childbirth to be visited by a health worker at least 3 times since birth. This type of research was descriptive quantitative. The quantitative data obtained from questionnaires, using T-test. The research sample was breastfeeding mothers in the village of Balecatur as the intervention group and breastfeeding mothers in the village of Ambarketawang as the control group. There are significant differences of knowledge, behavior in the treatment of post-partum mothers between the intervention group and the control group with significant value in total of $<0.05$, influenced by the role of cadres, social support, the role of health workers. Post partum visits conducted by community empowerment strategies, women as the main actors. The role of leaders, social support affect the success of efforts to increase postnatal visits among others disseminating information, provide examples, sensitize, motivate, guide, moving targets and the community and facilitating thus the knowledge, skills and increased public awareness can foster public participation in the postnatal visit.
\end{abstract}

Copyright () 2016 Institute of Advanced Engineering and Science. All rights reserved.

\section{Corresponding Author:}

Eny Retna Ambarwati,

Midwifery Academy of Yogyakarta, Indonesia

Email: enyretna@gmail.com

\section{INTRODUCTION}

Health development is very important in improving the quality of human resources such as the Millennium Development Goals (MDG's). Health development should be directed to the development of qualified human resources in terms of physical, mental, and social, that economically productive and socially so that the role of health promotion is very important [1].

Health promotion is one of the preventive measures in the health sector in Indonesia, which is aimed at changing people's behavior to become healthier. Maternal health is one of the main problems in the world. The fact is accommodated in the fifth MDG's targets among others: to improve maternal health [2].

The maternal mortality rate (MMR) is also one of the targets set out in the millennium development goals namely the fifth target of improving maternal health to be achieved by 2015 is to reduce up to $3 / 4$ the risk of maternal mortality. More than 50\% of Indonesia's populations are women, they live in rural areas. Most of them are in economic status and low education levels. This is one of the causes of maternal mortality rate (MMR) which is quite high at 307 per 100,000 births. Contributing factor are such as bleeding $28 \%$, eclamption $24 \%$, infections $11 \%$, and others $11 \%$ covering women's empowerment, educational background, socioeconomic families, communities, economic, values, culture, and low level of attention of men against postpartum mothers [3].

Post partum is likely to the occurrence of maternal death, so it needs to get health care during childbirth to be visited by a health worker at least 3 times since birth. Postpartum visits one of which aims for breastfeeding counseling (exclusive breastfeeding). WHO recommends to exclusively breastfeed their babies in the first 6 months after the birth [4]. 
The last data mentioned active mothers' breastfed only $33.09 \%$. This number is far from the target set by the national which reaches to $80 \%$. The achievement of these targets has been a problem and the solution by performing development in the field of health. Health development goals set by the Ministry of Health is the increased awareness, willingness and ability for each person in realizing the optimal degree of public health. Community analysis becomes expedient solution, in order to know the real issues. Health promotion has been established as a mandatory service for community health centers, so that the implementation of health promotion is the right time to become the commitment of all parties [5]. Three health promotion missions established by the Ministry of Health are such as empowerment, social support and advocacy will be used as a reference to compare intervened health promotion models adapted to the needs of society based on research results.

Based on observations of the researcher at the beginning of the study conducted at research sites, there are several factors that cause maternal health program is not optimal in its achievements, namely: maternal health knowledge and culture. Discussing culture is related to values, beliefs, attitudes, myths, even something supernatural / mystical and contrary to modern medical science. Conditions in the field, people still adhere to the culture and are recognized as a norm that must be obeyed. This phenomenon also shows that knowledge about the mother's health is still not maximal.

Society does not give priority to preventive efforts in accordance with the medical view, as a routine check, eating nutritious food. However, preventive measures are carried out more likely to view the culture, the behavior that is harmful to health. Resolving issues with health is always-curative means. Highly recommended preventive measures, due to more value added. Health promotion is one of the preventive measures. Because it is necessary for health promotion models appropriate for post partum mothers.

\section{RESEARCH METHOD}

Type of this research was mixed method combining descriptive quantitative [6]. Design of the research showed in Figure 1.

\section{Q1}

$\mathbf{X}$

Q2

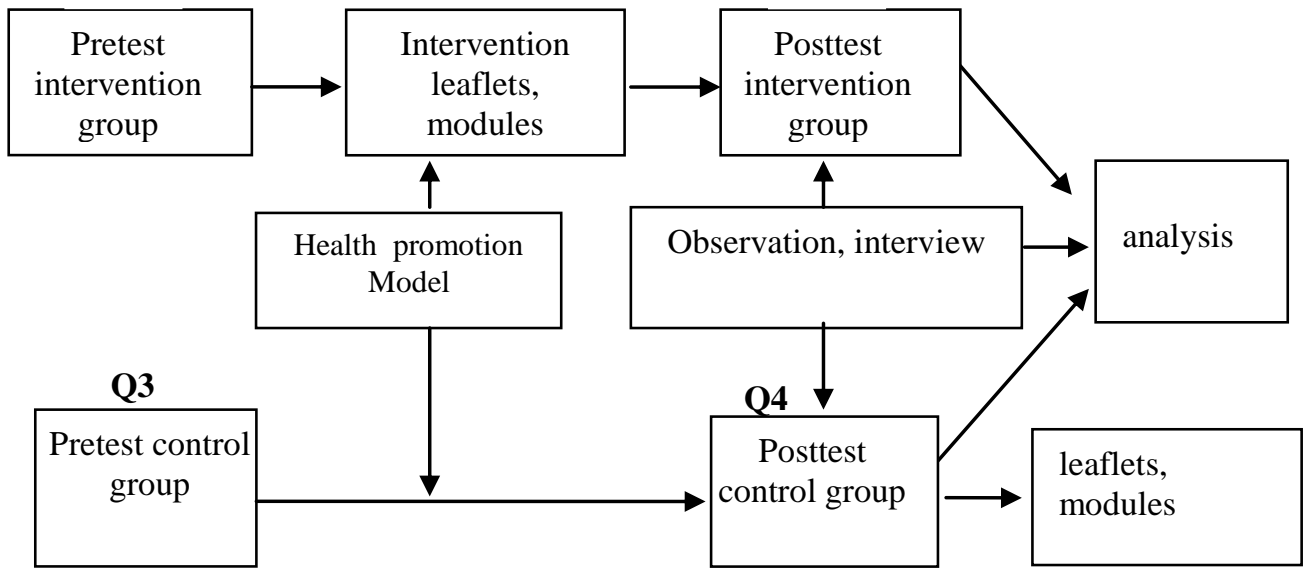

Figure 1. Research Design

Quantitative approach employed T-test [7]. Sample of this research were breastfeeding mothers in the village of Balecatur as the intervention group and breastfeeding mothers in the village of Ambarketawang as the control group.

\section{RESULTS AND ANALYSIS}

\subsection{Characteristics of Responden}

The Table 1 is based on the age of the respondents. In the intervention group the majority of respondents were aged 20-35 years as many as $26(86 \%)$ and the minority were mothers aged $<20$ and $>35$ years as many as $2(7 \%)$. While the majority of the control group of respondents were aged 20-35 years as many as $27(90 \%)$ and the minority mothers who were aged <20 years were as many as $1(3 \%)$.

Characteristics of respondents based on parity. Respondents in the intervention group at most give birth to her first child as many as $15(50 \%)$ people, while a minority of respondents gave birth to a fourth child as many as $1(3 \%)$ people. While the respondents in the control group at most gave birth to her first 
child as many as $18(60 \%)$ people, while the minority of respondents who gave birth to the fourth child were in total number of $1(3 \%)$ people.

Table 1. Characteristics of respondents

\begin{tabular}{lcccc}
\hline \multirow{2}{*}{ Characteristics } & \multicolumn{2}{c}{ Intervention } & \multicolumn{2}{c}{ control } \\
\cline { 2 - 5 } & $\mathrm{n}$ & $\%$ & $\mathrm{n}$ & $\%$ \\
\hline Age & 26 & 86 & 27 & 90 \\
20-35 years & 2 & 7 & 1 & 3 \\
$<20$ years & 2 & 7 & 2 & 7 \\
$>35$ years & & & & \\
Parity & 15 & 50 & 18 & 60 \\
first & 12 & 40 & 9 & 30 \\
second & 2 & 7 & 2 & 7 \\
three & 1 & 3 & 1 & 3 \\
fourth & & & & \\
Job & 3 & 10 & 5 & 17 \\
Government employees & 12 & 40 & 14 & 47 \\
Trader & 8 & 27 & 1 & 3 \\
self-employed & 7 & 23 & 10 & 33 \\
Farmer & & & & \\
\hline
\end{tabular}

Characteristics of respondents by job. Respondents in the intervention group showed a majority of work as traders as many as $12(40 \%)$ people, while those wives working as government employees respectively are in total of $3(10 \%)$ people. The majority of respondents in the control group do of work as traders as many as $14(47 \%)$ and those who work as self-employed, traders and farmers respectively

\subsection{Bivariate analisys}

Table 2 shows that there are significant differences of knowledge, behavior of mothers in the treatment of post-partum between the intervention group and the control group with significant value of $<0.05$. Model of health promotion given with counseling approach showed an increased in knowledge, behavior of postnatal care, parturition exercise and parturition care by using the media of leaflets, modules, and combination in the intervention group. The control group had increased even though there was not made counseling with the results of post-test higher than the pretest result, it is certainly not out of the role of health educators and independence of the puerperal mothers [8].

Table 2. Independent T Test Result

\begin{tabular}{|c|c|c|c|c|}
\hline Variable & Group & Mean & t value & Sig \\
\hline \multirow[t]{2}{*}{ Knowledge postnatal care } & Intervention & 7.90 & \multirow{2}{*}{2.041} & \multirow{2}{*}{0.046} \\
\hline & Control & 7.66 & & \\
\hline \multirow{2}{*}{$\begin{array}{l}\text { Knowledge gymnastics } \\
\text { parturition }\end{array}$} & Intervention & 8.46 & \multirow{2}{*}{2.355} & \multirow{2}{*}{0.022} \\
\hline & Control & 7.76 & & \\
\hline \multirow[t]{2}{*}{ Knowledge of breastfeeding } & Intervention & 27.90 & \multirow{2}{*}{2.324} & \multirow{2}{*}{0.024} \\
\hline & Control & 24.86 & & \\
\hline \multirow[t]{2}{*}{ Postnatal care behaviors } & Intervention & 28.80 & \multirow{2}{*}{3.121} & \multirow{2}{*}{0.003} \\
\hline & Control & 25.43 & & \\
\hline
\end{tabular}

Knowledge can be used to guide the development of evidence-based strategies to promote women's health behavior during the immediate postpartum period, which can be continued throughout the lifespan [9]. In this study, the researcher used counseling method individually by giving lectures, discussions, demonstrations and re-demonstration thus providing an opportunity of counseling to be a support system for mothers, to understand the level of ability and emotional state of mothers so that it can adjust to the situation of mothers in providing counseling and eventually can transfer the learning materials effectively [10].

Model of health promotion with counseling approach using leaflets media, modules and combination in the intervention group showed an increase that was influenced by the role of cadres, social support, the role of health workers. The application of the model of health promotion in breastfeeding mothers proved to provide considerable benefits for both the parturition mother, a higher increase among the intervention group than with the control group. After the research was given leaflets and modules. This is according to a research conducted by Pender, Murdaugh, \& Parsons [11] that health promotion is a theory 
that provides the exploration of factors which enable individuals to engage in health promotion where one can pursue better health or ideal health [11].

Health promotion in the form of health education (leaflets, reference books module) is very important and has great benefits to improve their skills and independence as well as the behavior of puerperal women and their families [12]. Advocacy on relevant agencies to foster togetherness of community leaders, health departments, village heads, to participate in improving health status can play an active role and implementing the program of health education [13].

The success of increase in puerperium visits are influenced by the role of mothers in the village, especially cadres, social Support, the role of health workers as a facilitator. Internally the roles of community leaders are very influential on the success of efforts to increase puerperal period visits. The leadership role of rural communities to disseminate information, provide examples, sensitize, motivate, guide, monitor, to move targets and society, as well as facilitating so as to improve the knowledge, skills and awareness, which in turn can foster public participation in the KIA program, especially puerperium visits. Public participation is the key to the success of community empowerment in the health field, including visits during childbirth.

The success of postpartum visits is supported by the increase of social support and social capital in the community. Social capital in the community in the village is a bond between individuals to one another is in nature for mutual help, including helping to overcome the difficulties of childbirth, puerperium, mothers and child health care, prevent the disease during puerperal. With coaching, training and facilitation of health workers (midwives) from the knowledge and skills of community health centers in an effort to prevent and deal with health problems, especially puerperium. This will have an impact on improving the ability of the community in identifying the problem, to know the local culture, plan activities, implement, monitor, and assess the success of efforts to increase puerperium visits.

With the existence of training this will improve the skills of the community, especially mothers in the practice of health care for mothers and children. The relationship between the role of community leaders, social capital, the role of health workers, the role of facilitator in improving puerperium visits can be explained as the image of model of health promotion as follows (Figure 2).

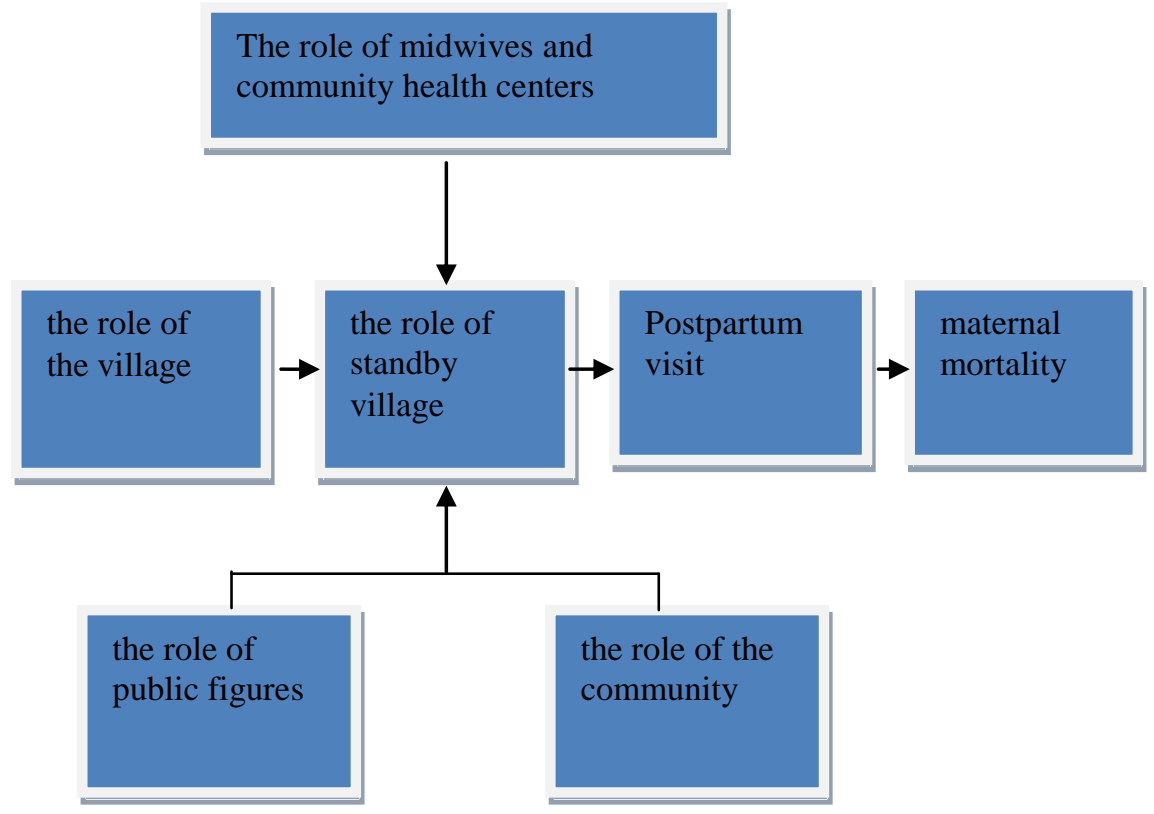

Figure 2. The model of health promotion

\section{CONCLUSION AND SUGGESTIONS}

Puerperal visits conducted by community empowerment strategies, women as the main actors. The role of leaders, social support affects the success of efforts to increase puerperium visits among others disseminate information, provide examples, sensitize, motivate, guide, moving targets and the community and thus facilitating the knowledge, skills and increased public awareness that can foster public participation in the puerperium visit. 
Need of training activities in order to improve the knowledge of health care workers in health promotion, so that there are same standards regarding the understanding and ability of health workers from the district to the village level of health promotion. Keep health educator for postpartum mothers by forming groups carried out in a sustainable manner. Coordination of health workers and the public, especially cadres should be maintained as a form of channel system in the current information in the community. There should be a further research conducted or similar research in other places by other researchers in order to obtain the correct health promotion model in order to suit the needs and conditions of the community.

\section{ACKNOWLEDGEMENTS}

Directorate General of Higher Education Ministry of National Education, Coordinator of Private Universities "Kopertis" in Region V Special Region of Yogyakarta, and Director of the Academy of Midwifery Yogyakarta.

\section{REFERENCES}

[1] Center for Health Promotion, "Global Commitment to Health Promotion of Ottawa-Jakarta-Nairobi Towards Healthy People", MOH, Jakarta, 2009.

[2] WHO, "MDGs: Millenium Development Goals", WHO, Geneva, 2005.

[3] The Ministry of Health of the Republic of Indonesia, "National Health System. Department of health", Indonesia, Jakarta, 2004.

[4] Cresswell, JW., "Research Design: Qualitative, Quantitative and Mixed Methods Approaches", SAGE Publications, pp. 169, 2003.

[5] Kerlinger, FN., "Principles of Behavioral Research. Moulds to five. Translation Landung R Simatupang", Yogyakarta, Gadjah Mada University Press, 2006.

[6] World Health Organization, "Report of The Expert Consultation on The Optimal Duration of The Exclusive Breastfeeding", Geneva, Switzerland, Department of Nutrition for Health and Development, Department of Child and Adolescent Health and Development, 2001.

[7] Center for Health Promotion, "The National Policy for Health Promotion", MOH, Jakarta, 2004.

[8] Bonuck K., Peter SA., Margaret MM., Kathy F., Marji GMD., Diane MMD., "Breast-Feeding Promotion Interventions: Good Public Health and Economic Sense”, Jurnal of perinatologi, vol/issue: 22(1), pp. 78-81, 2002.

[9] Fowles, E., Cheng, H., Mills, S., "Postpartum health promotion interventions: A systematic review", Nursing Research, vol/issue: 61(4), pp. 269-282, 2013.

[10] Moussa AA., Maria DK., Anne MH., "A qualitative study of the promotion of exclusive breastfeeding by health professionals in Niamey, Niger", International Breastfeeding Journal, vol. 5, pp. 8, 2010. doi:10.1186/1746-4358$5-8$.

[11] Pender, NJ., Murdaugh, CL., Parsons, MA., "Health promotion in nursing practice (6 ${ }^{\text {th }}$ ed.)", Upper Saddle River, NJ, Prentice Hall, 2010.

[12] Cheng, C., Fowles, E., Walker, L., "Postpartum maternal healthcare in the United States: A critical review", The Journal of Perinatal Education, vol. 15, pp. 34-42, 2006.

[13] Miller, V., Jane, C., "Guidelines for Advocacy”, Translator: Hermoyo, Obor Indonesia, Jakarta, 2005. 